Twenty-four only were reëxamined, and but nine of these after the lapse of two years from last treatment.

The remainder, we are told, "were well," and we are to accept the assertion, I presume, on faith. I can recall patients who were treated eight years ago by gradual dilatation, and they say to-day that they are well, and they will continue to so say intil enough recontraction has taken place to interfere with the urinary function. But I would not be justified in saying that they are well-cured.

It is taught, and I believe such teaching is correct, that a case of stricture of the urethra is not cured until the normal calibre of the urethra is established throughout its entire extent. On examining critically the cases of Dr. Newman referred to in this paper not one of them, according to my standard, was cured.

If we take $u p$ the cases of the other reporters who claim so much for electrolysis and analyze them, we come to the same conclusion that we do in Dr. Newman's cases.

Now, the point may be raised that my failure of success with electrolysis was due to a want, upon my part, of the correct appliances; also that I was lacking in technique and dexterity in the manipulation of urethral instruments. The first point cannot be maintained, for I secured the most approved apparatus. As to the other objections I have no reply to make. But this I do know, and from personal interviews with some of them, that the most expert genito-urinary surgeons and those having world-wide reputations, like myself have failed, after honest work, in deriving any good results from electrolysis in the treatment of urethral strictures.

After candid consideration and a fair amount of experience, I firmly believe that these reporters, and to be charitable with them, are laboring under a delusion, and what success they claim as being derived from electrolysis is secured purely by the dilating effect of their bougies. It will be observed that the most of their cases are only enlarged up to from $20 \mathrm{~F}$. to $28 \mathrm{~F}$., the amount of improvement that is ordinarily secured without much trouble by gradual dilatation. We know that strictures frequently, after being dilated up to a certain point, cease to dilate any further, when urethrotomy becomes necessary. Now, it will be observed, further, that the cases treated by electrolysis are only dilated up to a certain point ; none are dilated completely.

Among the hundred cases herein referred to are some in which it is stated that, after a filiform had failed to pass in other hands, an electrode bougie went through on the first attempt. That proves nothing, for the urethral canal is a very unreliable one, owing to its proneness to spasm, as all know who have had some experience. During the early part of this year I introduced a No. $18 \mathrm{~F}$. sound into a certain urethra without much trouble. Four days afterwards I could not introduce even a filiform. Upon the second attempt the surroundings were different, and the obstruction was purely spasmodic in its nature.

If electrolysis, in the treatment of urethral strictures, is " a delusion and a snare," I hope this paper will bring out the experience of those who can speak ex cathedra upon the subject, and if the consensus of opinions confirms my own, I then am glad that I have added my feeble effort to assist in pricking the bubble.

\section{THE USE OF LACTIC ACID IN CHRONIC SUPPURATIVE OTITIS.}

Read before the Medical Socinty of the District of Columbia,
March 7 , I888.

BY ISIDOR BERMANN, M.D.,

OF WASHINGTON, D. C.

Among the most troublesome and dangerous affections of the middle-ear we daily meet with, chronic suppuration must be mentioned as requiring our most energetic efforts towards effecting a cure. It is not only the unpleasantness of the mostly offensive discharge, although this is usually the cause of the patient's applying to us, but the actual danger of metastasis, that even when the discharge is flowing freely, always exists, which calls on us to use every means in our power not only to stop the discharge, but also to remove the cause of it. The danger is owing principally to the retention of smaller or larger quantities of pus in the cells of the mastoid process and it is very frequently, especially when the opening in the drum is not large, impossible to remove every particle of pus by syringing. This accumulation gets inspissated in the adjoining cells of the mastoid process and can remain there for years without doing apparently any harm, even while the ear, as far as can be seen by ocular inspection, is kept perfectly clear by syringing or instillations.

It is needless to mention here the different indications and various methods that have been recommended and are constantly in use for these troubles. No doubt a great many of them, as most of us have experienced, especially if the, cases come early enough into our hands, are quite effective in arresting the discharge, and we frequently see perforations of the tympanum heal up under their application. It is not to such cases I am alluding to-night, but to those that have resisted every effort of medication and persist in a steady malodorous discharge of a muco-purulent nature. They usually go hand in hand with somewhat larger perforations, and although the hearing may not have suffered to any great extent, give rise to the most unpleasant symptoms.

It must be taken for granted that the cause for this incessant suppuration lies in an affection of 
the bone, although usually one can neither see it, nor feel any carious bone with the probe. The specimens of necrotic portions of the middle and the internal ear that have been expelled after years of suffering, which eren the most skillful medical attention could not allay, are not often seen, and tio only rarely have we the good fortune to admire the wis medicatrix nature, when the patient brings some day a piece of bone to us which he has found after syringing the ear. The majority of such cases end fatally, unless operated on in time.

During my risit in Europe my attention was called to the use of lactic acid in chronic suppurative otitis media, and after my return I resolved to apply it in the first case in which it would be indicated. I did so, and was very agreeably surprised at the rapidity with which I was able to arrest the discharge. It was a case of very long standing, where both ears were affected and where everything possible under the sun had been applied, but in vain. In that first case, as I was not sufficiently acquainted with the effects of such applications, I made the patient come every day, and instilled the diluted lactic acid into both ears, leaving it there from ten to twenty minutes. The offensive odor disappeared completely after the first four days, not to return, and in the course of six weeks every trace of the discharge was gone, and as the drum showed an inclination to heal up, I accelerated this by applications of lapis mitigatus in substance. I afterwards directed the patient how to use the acid at home.

I have not the intention of taking up your valuable time by giving you a complete history of the cases that I have treated with lactic acid. $\mathrm{Be}$ it sufficient if I describe the way I found most effective, and assure you that if you will give it a trial in cases where it is indicated you will have every reason to be as satisfied with the results as I was.

On account of the acid macerating the epidermis with which it comes in contact and producing a very umpleasant soreness of the ear, if nothing worse, it is important to protect the meatus auditorius externus from such contact. After trying oil, vaseline, cocoa butter and other fatty compounds in vain, I found that by covering the meatus auditorius externus with a thin lining of paraffine I was enabled to leave even a 30 to 40 per cent. solution twenty minutes in the ear without producing the slightest irritation. It is well to begin with weak solutions and observe how the patients stand them. If the effect is satisfactory one can then go on gradually to stronger solutions of the acid which can be applied, if the patient is intelligent enough, by himself, and must be left at least twenty minutes in the ear. The paraffine must not have too low a melting point, the ear not being very sensitive to moderate heat, and can be applied with a camel's hair brush, care being taken that all those parts of the outer ear with which the acid|drugs: comes in contact be well protected. After the discharge is stopped it is not necessary to go on with the lactic acid, but keep the patient under observation, and insufflate boracic acid, finely powdered, from time to time. If the drum shows no inclination to heal up it will usually be found necessary, as well for protection as for improvement of the hearing, to insert artificial drums. Some patients' ears stand them very well and their hearing is much improved by wearing them; others resent a foreign body like that very energetically and respond very quickly with acute inflammation and intense painfulness. In such cases I have found that a layer of boracic acid, finely powdered, applied in such a way that it forms a somewhat thicker kind of artificial drum, is not only stood very well but also improves the hearing to quite a considerable degree.

[A few weeks before this paper appears I saw a lady who had been provided with such a layer of boracic acid to act as artificial drum, about six months ago, and found the boracic acid powder still in place, with a ring of wax dereloped around it and holding it in position.]

\section{USE OF ANTIPYRIN AND ANTIFEBRIN FOR HEADACHES.}

BY J. M. G. CARTER, M.D., SC.D., PH.D., OF WACKEGAN, ILL.

For some time now I have been using antipyrin and antifebrin in nervous headaches. My attention was first called to the use of antipyrin in these cases by Prof. Walter S. Haines, M.D. I have found a few cases of sick headache that would yield to this remedy, but generally in persons of nervous temperament. My cases have all been non-febrile. The remedy is prescribed in 5 -grain doses every hour until the headache ceases. Often one powder is sufficient, and rarely are more than two or three required.

I have been told that antipyrin has none of its depressing effect upon the heart in non-febrile cases. Such is not my observation. In frail nervous patients, especially in delicate females of nervous temperament, I find that antipyrin does disturb the heart's action, even in 3 -gr. and 5 -gr. doses. This effect of antipyrin followed notwithstanding the good effect of relieving the headache. To obviate this difficulty was a desirable point to gain and, remembering that there has not been so much complaint against antifebrin, in its disturbance of the heart, as against antipyrin, I determined to try its use. I was much pleased to find that, in cases where the antipyrin cannot be borne, the antifebrin acts admirably. I give the antifebrin in 3 -gr. or 5-gr. doses every hour until the headache ceases. Reference to the following five patients will illustrate the varied action of these 